\title{
QUATERNARY BASALTS FROM ROMANIA - CHARACTERISTICS AND NON-CONVENTIONAL USES
}

Marica S. ${ }^{1}$

${ }^{1}$ Raw Materials Laboratory, PROCEMA GEOLOGI, 136 Calea Grivitei, S1, 010707 Bucharest georock@georock.rdslink.ro

\section{ABSTRACT}

This paper presents an advanced stage of research work regarding the exploitation of natural volcanic rocks (basalt, andesites, tuffs) that are not to be polished but that can be cut into thin tiles and be cover with different inorganic and organic films. The basalt, andesite and tuff samples from some quarries proved to have very good cutting parameters, linear thermal expansions with a temperature between 5.67 and $8.85 \times 10^{6} \mathrm{C}^{-1}$ for basalts and andesites and between 0.05 and 3.82 $\times 10^{6} \mathrm{C}^{-1}$ for tuffs. The classic ceramic coating process used glaze with grinding fineness. The resulting surfaces are glossy, uniformly covered from a decorative aspect and by a variety of colour, suitable for various external and internal applications.

The non-conventional coating by oxy-gas flame thermal spraying process on basalt frits with a grinding fineness between 100 and $70 \mu \mathrm{m}$, resulted in rough, dark coloured surfaces, suitable for floors with high compressive strengths.

\section{INTRODUCTION}

The Quaternary basaltic rocks have a rare presence among the recent magmatic products located of the eastern part of the Alpine-Carpathian-Himalayan mountain chain on the Romanian territory. The emergence region of the most recent basalt products is situated in two regions: one in the center of the country, of the Persani Mountains, situated about $70 \mathrm{~km}$ away from the city of Brasov; the second area is of the Banat region, situated in the western part over of the country [1] (Figure 1).

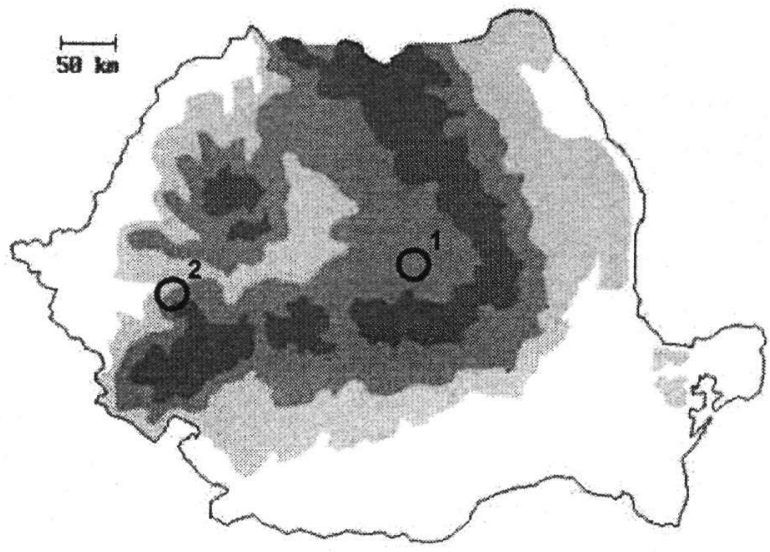

Figure 1. The emplacement of the two investigated areas: [1] Persani Mountains, [2] Banat region

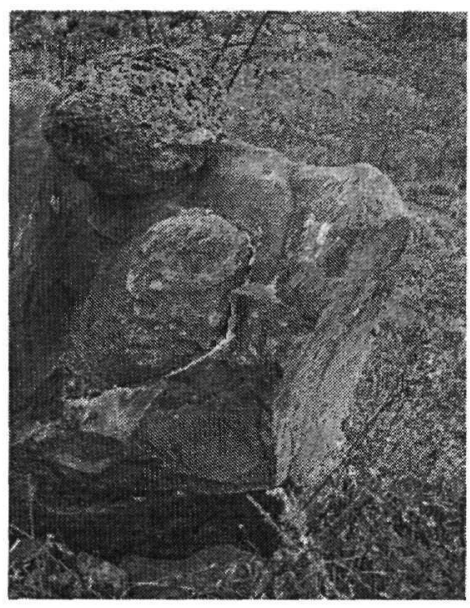

Figure 2. Volcanic bomb and scoria fragment in the Banat deposits 


\section{GEOLOGICAL INFORMATION}

The basalt products are the result of the intraplate magmatic activity in the Transylvanian - Pannonian block from Romania and Hungary, following alpine consolidations. Volcanic break out centres generated along a NE-SW alignment that marks fractures of the lithosphere belonging to the most recent geological periods, continuing south of the Danube. Racos zone from Persani Mountains is the best known and spectacular zone with typical features and a lot of varieties of basaltic rocks.

The volcanic activity in these regions took place from the Badenian to the end of the Pleistocene. Moments of paroxysm alternated calm phases. Tectono - genetic interpretation of the geology of the Eastern Carpathians is linked to the presence of continental lithosphere below a the Neogene volcanic arch. The presence of this represents an advanced stage in the evolution of the compression - subduction activity that took place at the boundary of two large tectonic plates, demonstrated to have been existed on the territory of Romania at the end of the Pliocene and the beginning of the Quaternary periods.

The lavas emitted during such an activity had basaltic affinity, but it were, mostly, quite viscous and accompanied by large quantities of gases, which determine the explosive and permanent character of the activity. The activity consisted in rhythmic and continuous explosions, of lava rich in gases and vapor. This resulted in fragmentation of the lava and the formation of bombs and scorias (Fig. 2).

The presence of olivine and quartz in basalts of Persani is an argument for classifying these rocks into the "olivine basalts" the basanite - tephrite field [4]. According to the scientific classification chart of igneous rocks (Quartz, Sodic feldspar, Plagioclase, Feldspatoidite) the studied sampled are classified into the basanite tephrite field) .

The petrography and mineralogical characteristics, rendered from geological research and microscopic studied are sand, common for all basalts types. They structure a megascopic appearance of black or brownish or reddish color for scorias, with massive, vacuolar or scoria textures. The chemistry of all studied basaltic lavas confirmed their alkaline character, similar to that of many types of basalt in the world [1] .

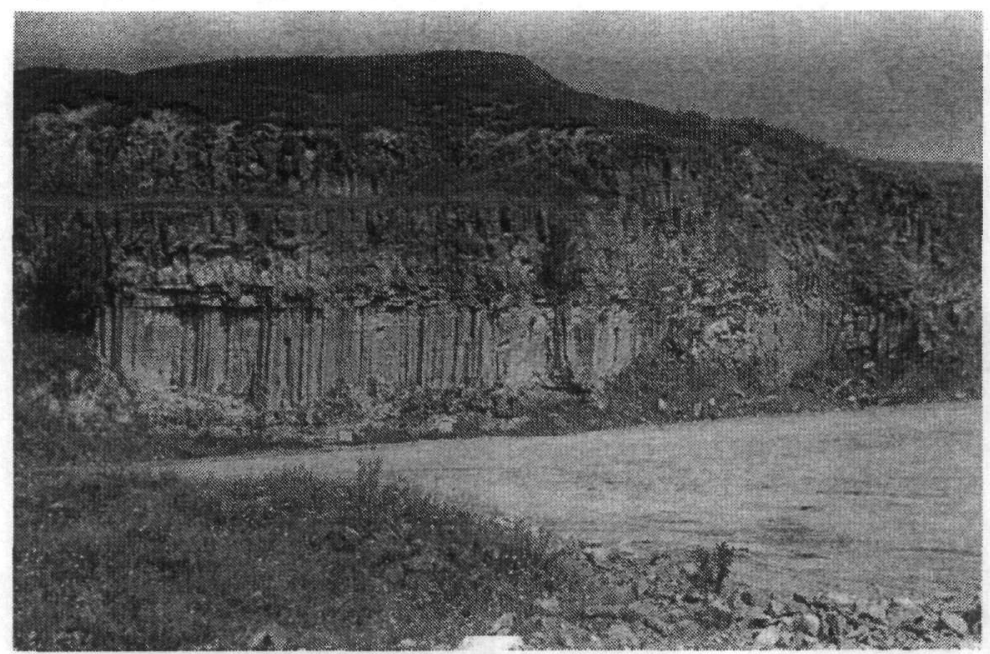

Figure 3. One of closed deposit in the Banat region

\section{METHODOLOGY}

This paper presents an advanced stage of research work regarding the exploitation of natural basaltic rock quarries that are not to be polished, but that can be cut into thin tiles. There were 10 open and middle quarries of such basaltic deposits in Romania (Fig.3). The research methods used 
more as follows: select of some small blocks cut out of the basaltic rocks, cutting of thick samples with sizes between 25 and 375 square centimeters, mineralogical and dilatometric determinations, selection of raw materials for frits and glaze, establishment glaze formulae with addition of ground basalts of rock up to $26 \%$ and characteristic determination (grinding fineness, viscosity, liter weight.) [2]

\section{RESULTS}

To obtain new and non-conventional products - namely the glazed basalt tiles - the basalt cut slab were subjected to different tests in order to define the properties of these rocks and to compare them with similar already-known products such as ceramic floor tiles. The tests proved that basalt tiles have got better properties than floor tile bodies. The experiments performed included three processes, coating with frit glazing and classic kiln baking, cold coating and non-conventional coating.

The basalt proved to present very good cutting parameters and linear thermal expansion in a temperature range of 5.67 and $8.85 \times 10^{6} \mathrm{C}^{-1}$ for basalts and andesites and 0.05 and $3.82 \times 10^{6} \mathrm{C}^{-1}$ for tuffs. The classic ceramic coating process used glazes with grinding fineness of $0.16 / 0.20 \mathrm{~mm}$, the liter weight of $1620 \mathrm{~g} / \mathrm{l}$ and Galenkamp fluidity of $5-6^{\circ} \mathrm{C}$. The resulting surfaces are glossy, uniformly covered from a decorative aspect and by a variety of colors, resistant to various external and internal impacts.

To obtain the final products - namely the glazed basalt tiles - the basalts samples have been subjected to physico- mechanical and physico-ceramic tests (Fig. 4, 5) in order to get acquainted the properties of these rocks and to compare them with similar, already known products as are, the ceramic floor tiles.

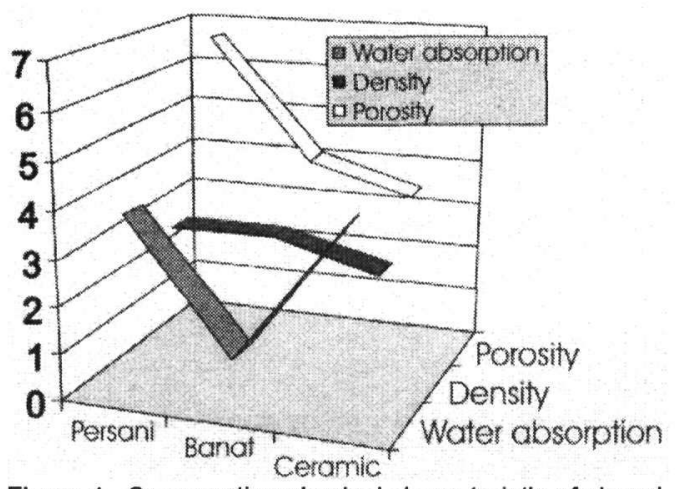

Figure 4. Comparative physical characteristic of glazed basalt tiles and ceramic tiles

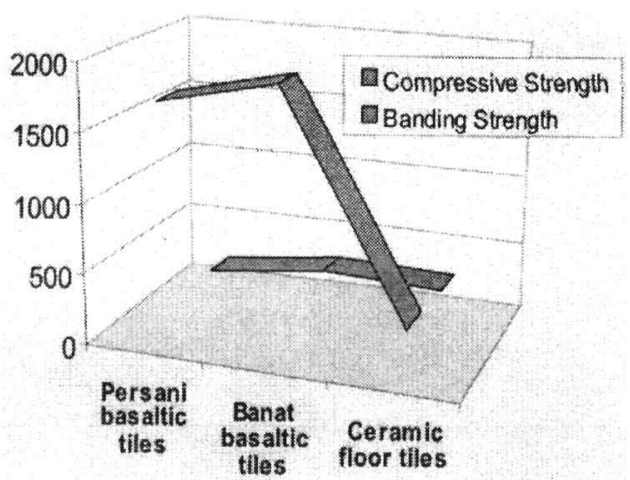

Figure 5. Comparative mechanical characteristic of glazed basalt tiles and ceramic tiles

The obtained results, on the two variants of rocks using three technological methods and film covering were very satisfactory, even exceptional so, more especially for the tiles with basalt vacuole support, supporting the exposal for a domestic production for a domestic production of such tiles.

The covering with easily fusible glazes took into account the physico - chemical and mineralogical characteristics. The behaviour to thermal treatment (Fig.6). 


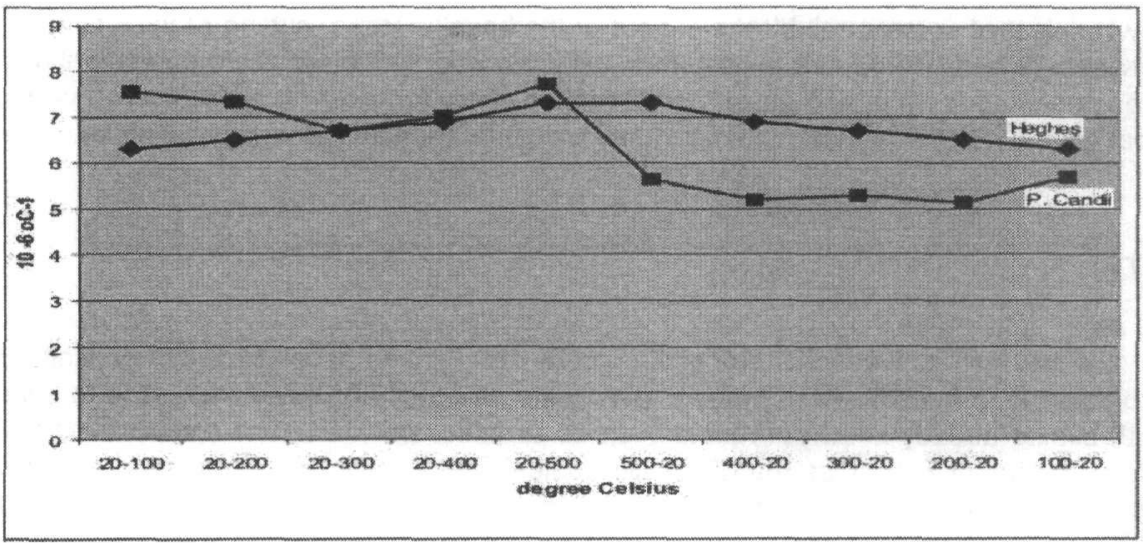

Figure 6. Dilatometric curves of basaltic samples

Two main direction for making glazing were firing at temperature between 920 and $980^{\circ} \mathrm{C}$ and the second method was the used of low temperature glazes( glossy opaque or mat ) whose melting temperature is between 950 and $1000^{\circ} \mathrm{C}$.

The third method applied included ornamental and functional organic coverings. These are combined coverings of the vacuolar basalt plates and included stiffening materials in the hollows the basalt tiles that have been cut. The following stiffening materials may be used: inorganic or organic granules, fibre wastes, broken glasses, slags, industrial sub- products (steriles, basalt sand, red mud). [3]

The cold coating process used organic and epoxy resins, various wastes and ceramic pigments The resulting surfaces display a rustic aspect, suitable interior decorations. The applied phases and technological methods were the following:

- gravimetric measurements of raw materials of ceramic frits;

- preparing frits;

- covering tiles;

- drying products in laboratory oven (Fig.7).

The techniques of glazes applications included:

- stencil process (Fig.8);

- manual brushing process;

- pulverizing process;

- painting.

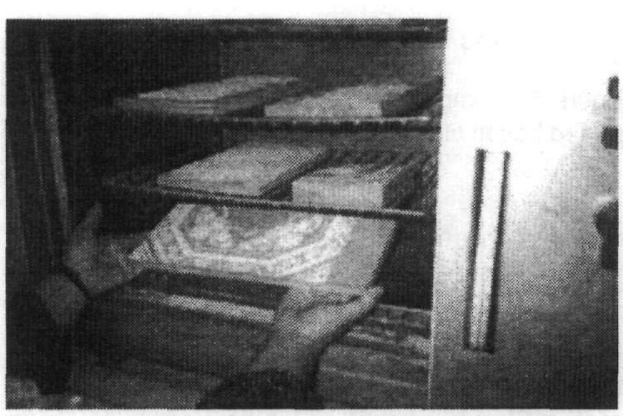

Figure 7. Drying process of glazed tiles samples

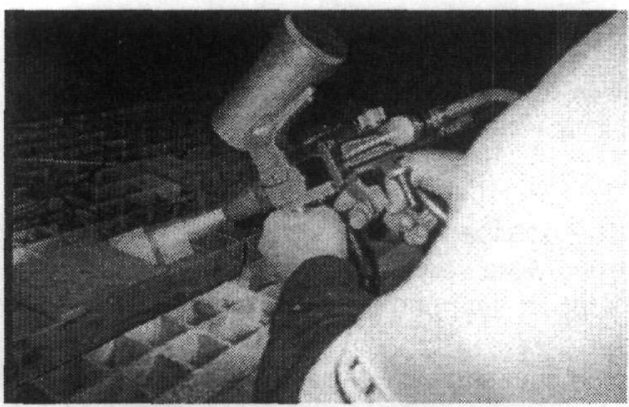

Figure 8 . The cover of basaltic tiles with glazes by stencil process 
The special characteristics of basalt rocks may be an ideal material base for obtaining certain slabs/tiles with various dimensions and formats that gain a special appearance after having been coated with glazes. (Fig. 9). [3]
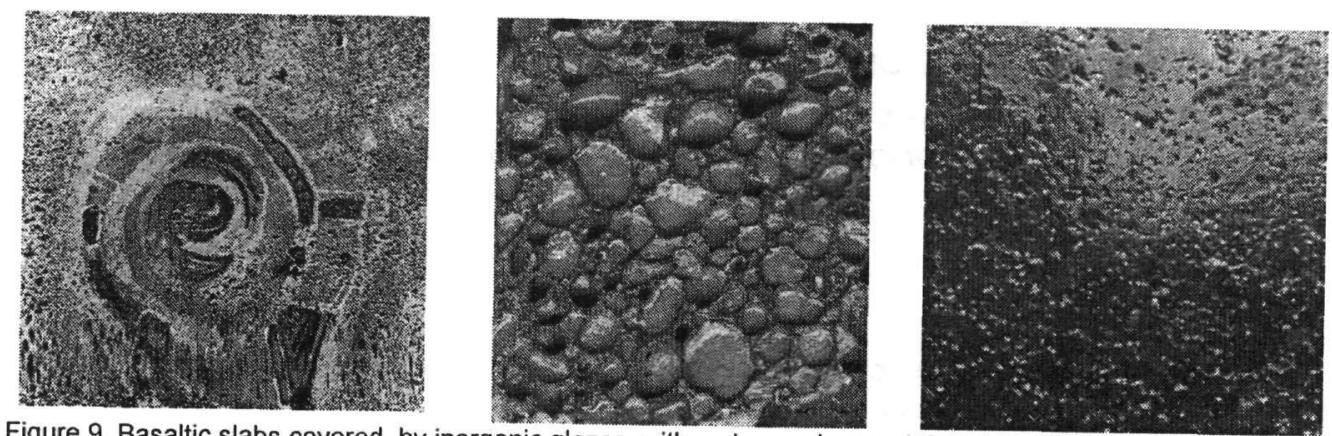

Figure 9 . Basaltic slabs covered by inorganic glazes, with various colors and decorative aspects

\section{CONCLUSIONS}

The special characteristics of Quaternary basaltic rocks from Romania can be an ideal material base for obtaining decorative and multifunctional tiles with various dimensions and formats that gain a special appearance after having been coated with glazes.

Such tiles may be used in various fields such as: interior and exterior cladding of walls and floors with intense circulation, bathrooms, entrance halls, stairs or other interior facing walls or other surfaces in special environments that are exposed to frost, heat or those exposed to corrosion and
acids.

The non-conventional coating by oxy-gas flame thermal spraying process used basalt frits with a grinding fineness between 100 and $70 \mu \mathrm{m}$, resulting in rough, dark colored surfaces, suitable for
floors with high compressive strengths.

\section{REFERENCES}

[1] Marica, S. 1991. Geological and technological study for determination of Heghes Hill scorias reserves Racos PROCEMA Geological Archives - nr.628, 629

[2] Marica, S., Kovacs, G., Ciornei, N. 2003. Advanced methods for obtaining of new decorative products with high resistances from natural Romanian rocks, RELANSIN project

[3] Marica, S., Cetean,V., Glisici, A., Kovacs, G. Ornamental glazed tiles based Romanian Plioquaternary Basalts. Sixth ECER'S Extended Abstracts, Brighton, volume 2, pag.321-323 [4] Peltz, S., Vasiliu, C., Bratosin, I. 1981. Petrology of Romanian Plioquaternary Basaltic Rocks. Geol. Institute
Year Book, p.133-137 [5] Radulescu, D. 1976. Volcanoes - Nowadays and in the Geological Past, Technical Publishing House, Bucha-
rest 